\title{
Article \\ Screening and Molecular Identification of Bacteria from the Midgut of Amphimallon solstitiale Larvae Exhibiting Antagonistic Activity against Bacterial Symbionts of Entomopathogenic Nematodes
}

\author{
Marcin Skowronek $^{1, * \mathbb{D}}$, Ewa Sajnaga ${ }^{1} \mathbb{D}$, Waldemar Kazimierczak ${ }^{1} \mathbb{D}$, Magdalena Lis ${ }^{1} \mathbb{D}$ and Adrian Wiater and $^{2, * \mathbb{D}}$ \\ 1 Laboratory of Biocontrol, Production and Application of EPN, Centre for Interdisciplinary Research, \\ The John Paul II Catholic University of Lublin, 20-708 Lublin, Poland; ewa.sajnaga@kul.pl (E.S.); \\ waldemar.kazimierczak@kul.pl (W.K.); magdalena.lis@kul.pl (M.L.) \\ 2 Department of Industrial and Environmental Microbiology, Institute of Biological Sciences, \\ Maria Curie-Sklodowska University, 20-033 Lublin, Poland \\ * Correspondence: marcin.skowronek@kul.pl (M.S.); adrian.wiater@mail.umcs.pl (A.W.)
}

\section{check for}

updates

Citation: Skowronek, M.; Sajnaga, E.; Kazimierczak, W.; Lis, M.; Wiater, A.

Screening and Molecular

Identification of Bacteria from the

Midgut of Amphimallon solstitiale

Larvae Exhibiting Antagonistic Activity against Bacterial Symbionts of Entomopathogenic Nematodes. Int J. Mol. Sci. 2021, 22, 12005. https:// doi.org/10.3390/ijms222112005

Academic Editor: Andreas Burkovski

Received: 30 September 2021

Accepted: 2 November 2021

Published: 5 November 2021

Publisher's Note: MDPI stays neutral with regard to jurisdictional claims in published maps and institutional affiliations.

Copyright: (c) 2021 by the authors. Licensee MDPI, Basel, Switzerland. This article is an open access article distributed under the terms and conditions of the Creative Commons Attribution (CC BY) license (https:// creativecommons.org/licenses/by/ $4.0 /)$

\begin{abstract}
Entomopathogenic nematodes (Rhabditida: Steinernematidae and Heterorhabditidae) are a group of organisms capable of infecting larvae of insects living in soil, including representatives of the family Scarabaeidae. Their insecticidal activity is related to the presence of symbiotic bacteria Xenorhabdus spp. or Photorhabdus spp. in the alimentary tract, which are released into the insect body, leading to its death caused by bacterial toxins and septicemia. Although the antibacterial activities of symbionts of entomopathogenic nematodes have been well described, there is insufficient knowledge of the interactions between these bacteria and microorganisms that naturally inhabit the alimentary tract of insects infested by nematodes. In this study, 900 bacterial strains isolated from midgut samples of Amphimallon solstitiale larvae were tested for their antagonistic activity against the selected five Xenorhabdus and Photorhabdus species. Cross-streak tests showed significant antibacterial activity of 20 isolates. These bacteria were identified as Bacillus [Brevibacterium] frigoritolerans, Bacillus toyonensis, Bacillus wiedmannii, Chryseobacterium lathyri, Chryseobacterium sp., Citrobacter murliniae, Enterococcus malodoratus, Paenibacillus sp., Serratia marcescens and Serratia sp. Since some representatives of the intestinal microbiota of $A$. solstitiale are able to inhibit the growth of Xenorhabdus and Photorhrhabdus bacteria in vitro, it can be assumed that this type of bacterial interaction may occur at certain stages of insect infection by Steinernema or Heterorhabditis nematodes.
\end{abstract}

Keywords: midgut microbiota; bacterial interactions; entomopathogenic nematodes; Xenorhabdus; Photorhabdus; Amphimallon solstitiale

\section{Introduction}

Representatives of the genera Photorhabdus and Xenorhabdus ( $\gamma$-Proteobacteria, Morganellaceae) occur naturally in two types of environments. One of them is the intestinal lumen of free-living third-stage juveniles of soil-inhabiting entomopathogenic nematodes (EPNs). Photorhabdus species form mutualistic relationships with nematodes of the genus Heterorhabditis, while Xenorhabdus are symbionts of nematodes from the genus Steinernema [1]. Infective juveniles actively seek out suitable hosts, i.e., larvae of insects from the Scarabaeidae family, in the surface soil layer and enter their bodies through natural openings (mouth, anus, tracheae, or spiracles) [2]. After entering the insect, nematodes release bacteria through regurgitation (Heterorhabditis) or defecation (Steinernema) into the hemocoel [3]. Initially, this cavity and next the entire larval cadaver become another habitat of nematode-associated bacteria. Photorhabdus and Xenorhabdus bacteria produce numerous enzymes that decompose insect tissues, e.g., proteases, lipases, hemolysins, and chitinases, which enriches the environment with nutrients thereby supporting rapid growth of bacteria 
and nematodes [4]. EPN bacteria can dominate this habitat, as they are able to produce numerous bacteriocins and other substances with antibacterial properties [5-7].

Although the activities of nematode symbionts during infection have been quite well explored, there is almost no knowledge about the mutual relationships between these bacteria and microorganisms constituting the insect gut microbiota. Noteworthy, such interactions must be considerably limited in the early stage of infection, since nematodes that have entered the insect's gut through natural openings from the external environment penetrate the hemocoel and release their bacterial symbionts in this body area. Therefore, there is a physical barrier separating the gut microbiota from the nematode-associated bacteria developing in the hemolymph. However, this barrier leaks as nematodes penetrate and damage the intestine. It has been found that, during the early phase of infection of Manduca sexta by Steinernema carpocapsae, many species of gut microbes are translocated into the hemocoel, where they are initially present together with Xenorhabdus nematophila released by nematodes [8]. It is only between 18 and $24 \mathrm{~h}$ after the onset of infection that $X$. nematophila becomes quantitatively dominant, while bacterial species originating from the insect gut gradually disappear, although some (in particular Enterococcus faecalis) are relatively resistant to $X$. nematophila antibiotics and can be found in the hemolymph even after $48 \mathrm{~h}$.

Noteworthy, the gut wall in insects infested with EPNs is not only leaky due to the damage induced by the nematode but also unstable, as bacteria released by nematodes produce enzymes that decompose insect tissues, including the wall of the digestive system. It has been found that, already at a very early stage of the Photorhabdus luminescens infection of $M$. sexta larvae, bacteria begin their growth in a region between the basal lamina and the midgut epithelium cells. In these conditions, Photorhabdus express a number of toxins (e.g., gut-active Toxin complex A (Tca) and an RTX-like metalloprotease PrtA). This induces massive programmed cell death of the midgut epithelium [9]. Similarly, Photorhabdus temperata is able to attach to the same space underneath the basal lamina in the midgut epithelium of the sugarcane stalk borer Diatraea saccharalis. It is suggested that the function of the $P$. temperata subpopulation that migrates to the midgut tissue is to inhibit the main source of immediate competitors, i.e., the midgut luminal microbiota [10]. In some cases, direct contact between nematode-associated and insect bacteria may occur early during the nematode infection, since it has been shown that nematodes can release their bacterial symbionts to the intestine, not reaching the hemocoel. Using GFP-labeled X. nematophila bacteria, it was found that some $S$. carpocapsae infective juveniles released its bacterial symbionts already in the alimentary tract of Spodoptera littoralis larvae [11].

Summarizing, the midgut microbiota of insects infected by EPNs can potentially interact with bacterial nematode symbionts at various stages of infection. Since some insect gut bacteria are capable of inhibiting the growth of Xenorhabdus or Photorhabdus bacteria, their activity may be one of the lines of defense of the insect host against nematode infection. Elucidation of the interactions between antagonistic groups of bacteria during EPN infection may provide a more complete picture of its course, which will help to understand insect defense mechanisms against nematode attack.

In this study, we describe screening of bacterial strains from $A$. solstitiale midgut for antibacterial activity against five EPN symbionts of the genera Xenorhabdus and Photorhab$d u s$. Although the presence of strains with such activities in the alimentary tract of insect larvae does not fully prove the occurrence of this type of interactions in vivo, it certainly makes this phenomenon highly probable.

\section{Results}

\subsection{Cross-Streak Tests}

At the beginning of the study, 150 bacterial strains were randomly isolated from midguts sampled from 10 A. solstitiale individuals (L2 and L3 larvae freshly collected from the natural environment). Next, potential antibacterial properties of these isolates were investigated using cross-streak tests against the following EPN bacteria species: 
Xenorhabdus bovienii, X. budapestensis, X. kozodoii, X. nematophila, and P. temperata (Figure 1). Four isolates (denoted as AT4 L2 01, AT5 L2 01, AT5 L2 02, and AT5 L2 04) were able to inhibit the growth of the selected bacteria species (Table 1). Another 750 bacterial strains were isolated from the midguts of larvae that had survived the 12-day exposure to EPNs. The aim of the use of midguts of larvae subjected to this type of pressure was to increase the probability of obtaining isolates able to inhibit the growth of nematode symbions. $66 \%$ of insect larvae exposed to IJ of Heterorhabditis megidis as well as $57 \%, 73 \%, 63 \%$, and $60 \%$ of larvae exposed to Steinernema arenarium, S. bicornutum, S. carpocapsae, and S. kraussei, respectively, survived the EPNs exposure. The determination of the antibacterial activity of the isolates with the use of cross-streak tests showed that the highest number of strains inhibiting the growth of the selected EPN bacteria strains (11) was isolated from the midgut of larvae subjected to the exposure to S. arenarium. Additionally, three isolates originating from larvae exposed to $S$. kraussei and two from larvae exposed to H. megidis were positive (Table 1).

In the cross-streak test, some isolates from the midguts of $A$. solstitiale larvae were able to completely inhibit the growth of the selected nematode symbionts over the entire surface of Petri dishes. None of these bacteria completely inhibited the growth of all EPN bacteria strains used in the cross-test, but strain ATK3 L3 01 was able to inhibit the growth of 4 out of the 5 species. X. bovienii and X. nematophila were the most sensitive to the antimicrobial activity of the isolates. The growth of $X$. bovienii and $X$. nematophila was completely inhibited by 12 and 9 isolates, respectively. In turn, P. temperata was characterized by the lowest susceptibility to growth inhibition. Only 5 isolates were able to prevent the growth of these bacteria, and the inhibition zones were significantly smaller than those of Xenorhabdus bacteria.

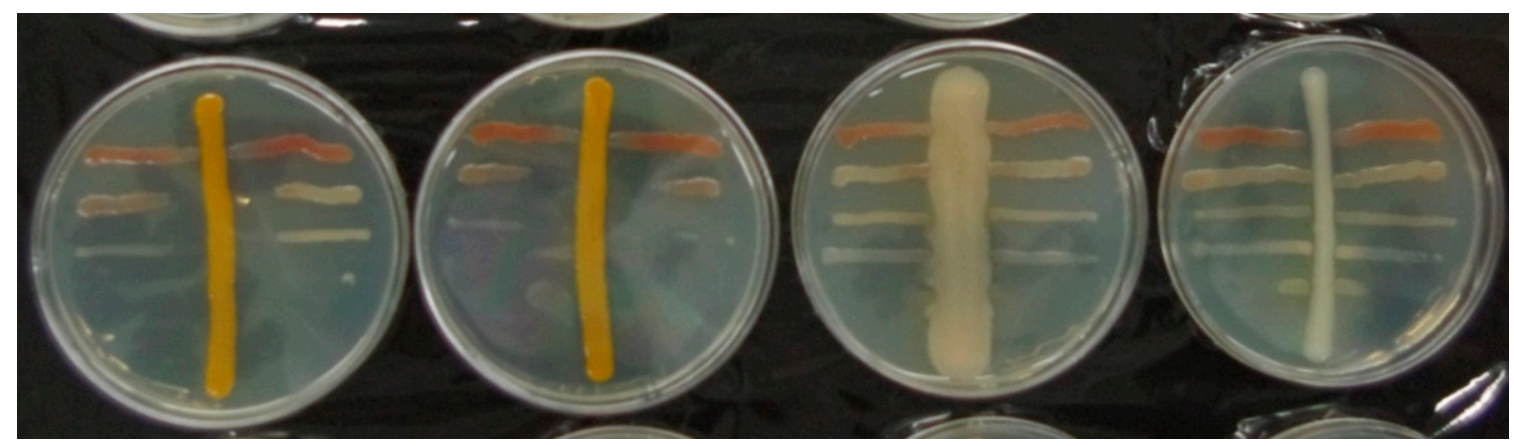

Figure 1. Cross-streak tests between A. solstitiale midgut isolates and EPN symbionts. Horizontal streaks-Xenorhabuds or Photorhabdus, vertical streak-midgut isolate. Plates on the left-isolates with high antibacterial activity against EPN bacteria strains (Chryseobacterium sp.); plates on the right-no inhibition effect.

Table 1. Cross-streak tests between selected $A$. solstitiale midgut isolates and five EPN symbionts.

\begin{tabular}{|c|c|c|c|c|c|}
\hline \multirow{2}{*}{ Strain ID * } & \multicolumn{5}{|c|}{$\begin{array}{c}\text { Size of Inhibition Zones (mm) } \\
\text { Left Inhibition Zone I Right Inhibition Zone }\end{array}$} \\
\hline & P. temperata & X. kozodoii & X. bovienii & X. nematophila & X. budapestensis \\
\hline AT4 L2 01 & $0 \mid 0$ & $0 \mid 0$ & $26 \mid 23$ & no gr. ${ }^{* *}$ no gr. & no gr. $\mid 22$ \\
\hline AT5 L2 01 & 918 & $11 \mid 12$ & no gr. I no gr. & no gr. I no gr. & 23 | no gr. \\
\hline AT5 L2 02 & $5 \mid 7$ & $9 \mid 10$ & no gr. I no gr. & no gr. 128 & $12 \mid 12$. \\
\hline AT5 L2 04 & $0 \mid 0$ & 919 & no gr. I no gr. & 21 I no gr. & $12 \mid 12$ \\
\hline ATA3 L3 05 & $2 \mid 2$ & 916 & no gr. I no gr. & 27 I no gr. & $22 \mid 19$ \\
\hline ATA6 L3 01 & $0 \mid 0$ & $0 \mid 0$ & $20 \mid 19$ & $13 \mid 14$ & $0 \mid 0$ \\
\hline ATA6 L3 02 & $0 \mid 0$ & $0 \mid 0$ & 23 | no gr. & no gr. I no gr. & $0 \mid 0$ \\
\hline ATA7 L3 01 & $0 \mid 0$ & $0 \mid 0$ & no gr. I no gr. & 22 I no gr. & $0 \mid 0$ \\
\hline ATA7 L3 02 & $0 \mid 0$ & $9 \mid 11$ & $21 \mid 23$ & 32 I no gr. & $15 \mid 9$ \\
\hline
\end{tabular}


Table 1. Cont.

\begin{tabular}{|c|c|c|c|c|c|}
\hline \multirow{2}{*}{ Strain ID * } & \multicolumn{5}{|c|}{$\begin{array}{c}\text { Size of Inhibition Zones (mm) } \\
\text { Left Inhibition Zone I Right Inhibition Zone }\end{array}$} \\
\hline & P. temperata & X. kozodoii & X. bovienii & X. nematophila & X. budapestensis \\
\hline ATA7 L3 03 & $0 \mid 0$ & $0 \mid 0$ & $22 \mid 23$ & $18 \mid 25$ & $0 \mid 0$ \\
\hline ATA7 L3 04 & $0 \mid 0$ & $10 \mid 11$ & no gr. I no gr. & 22 I no gr. & $12 \mid 12$ \\
\hline AMA4 L3 03 & $0 \mid 0$ & $17 \mid 18$ & no gr. I no gr. & no gr. I no gr. & $27 \mid 30$ \\
\hline AMA4 L3 04 & $0 \mid 0$ & $16 \mid 19$ & no gr. I no gr. & no gr. I no gr. & $24 \mid 25$ \\
\hline AMA6 L3 01 & $0 \mid 0$ & $0 \mid 0$ & no gr. I no gr. & no gr. I no gr. & 28 | no gr. \\
\hline AMA7 L3 01 & $4 \mid 6$ & $0 \mid 0$ & 718 & 717 & 313 \\
\hline ATK3 L3 01 & $0 \mid 0$ & no gr. I no gr. & no gr. I no gr. & no gr. I no gr. & no gr. I no gr. \\
\hline ATK4 L3 01 & $0 \mid 0$ & 716 & no gr. I no gr. & no gr. I no gr. & no gr. I no gr. \\
\hline AMK6 L3 01 & $0 \mid 0$ & $0 \mid 0$ & no gr. I no gr. & $11 \mid 14$ & $28 \mid 14$ \\
\hline ATH3 L2 10 & $0 \mid 0$ & $16 \mid 18$ & $25 \mid 21$ & no gr. I no gr. & no gr. $\mid 25$ \\
\hline AMH2 L2 03 & $1 \mid 1$ & 816 & $12 \mid 12$ & 617 & $12 \mid 13$ \\
\hline
\end{tabular}

* Strain ID coding: 2nd letter in strain ID: M-bacteria isolated in microaerobic conditions; T-bacteria isolated in aerobic conditions. 3rd letter in strain ID: A. solstitiale larvae exposed to: A-S. arenarium; K-S. kraussei; H-H. megidis. L2 or L3: developmental stage of the nsect larva. ${ }^{* *}$ no gr.-no growth (complete inhibition of bacterial strain growth).

\subsection{Maximum Inhibitory Dilution Tests}

The next stage of the study consisted in assessment of the ability of post-culture filtrates of isolates selected in the previous stage to inhibit EPN bacteria growth. Maximum inhibitory dilution (MID) tests were used for this purpose. The tests showed the EPN bacteria inhibitory ability of post-culture filtrates of 9 isolates from $A$. solstitiale midguts (Figure 2). In most cases, however, only partial growth inhibition of only some species (most often X. kozodoii) was recorded. Complete or almost complete inhibition of the growth of several EPN bacteria species was detected only in the case of undiluted filtrates from 2 isolates, i.e., AT4 L2 01 and AMH2 L2 03.

The results of the MID tests were statistically analyzed (one-way ANOVA, Tukey's HSD test). The supernatant dilution of all (except ATK L3 01) isolateshad a significantly influenced P. temperata growth (ANOVA, $\mathrm{F}_{14,4} \geq 7.201, p<0.005$ ). The undiluted supernatant of the AT4 L2 01 isolate completely inhibited the growth of $P$. temperata ( $t$-test, $\left.t_{4}=46.315, p<0.001\right)$. The undiluted supernatant of the AMA4 L3 03 isolate exerted the lowest inhibitory effect on $P$. temperata growth $\left(t\right.$-test $\left.t_{4}=3.299, p<0.05\right)$.

The supernatant dilution of all the isolates had a statistically significant influence on $X$. kozodoi growth (ANOVA, $\mathrm{F}_{14,4} \geq 7.202, p<0.05$ ). The undiluted supernatant of the AT4 L2 01 isolate caused almost complete inhibition of $X$. kozodoi growth $\left(t\right.$-test, $t_{4}=137.756$, $p<0.001)$. In the undiluted supernatant group AMH2 L2 03 isolate exerted the lowest inhibitory effect on $X$. kozodoi growth ( $t$-test $\left.t_{4}=4.377, p<0.05\right)$.

The supernatant dilution of AMH2 L2 03, AT4 L2 01, AT5 L2 04, ATA6 L3 01 and ATK L3 01 had a statistically significant influence on X. budapestensis growth (ANOVA, $\mathrm{F}_{14,4} \geq 5.584, p<0.05$ ). The undiluted supernatant of the AMH2 L2 03 isolate caused almost complete inhibition of $X$. budapestensis growth ( $t$-test, $\left.t_{4}=14.935, p<0.001\right)$. In the undiluted supernatant group, the supernatant of the AMA4 L3 04 isolate exerted no inhibitory effect on $X$. budapestensis growth ( $t$-test $\left.t_{4}=0.127, p>0.05\right)$.

The supernatant dilution of all the isolates, except AMA6 L3 01 and AMH2 L2 03, had a statistically significant influence on $X$. nematophila growth (ANOVA, $F_{14,4} \geq 8.026$, $p<0.05)$. In the undiluted supernatant group, the supernatant of the AMA6 L3 01 isolate exerted no inhibitory effect on $X$. nematophila growth ( $t$-test $\left.t_{4}=0.682, p>0.05\right)$. 

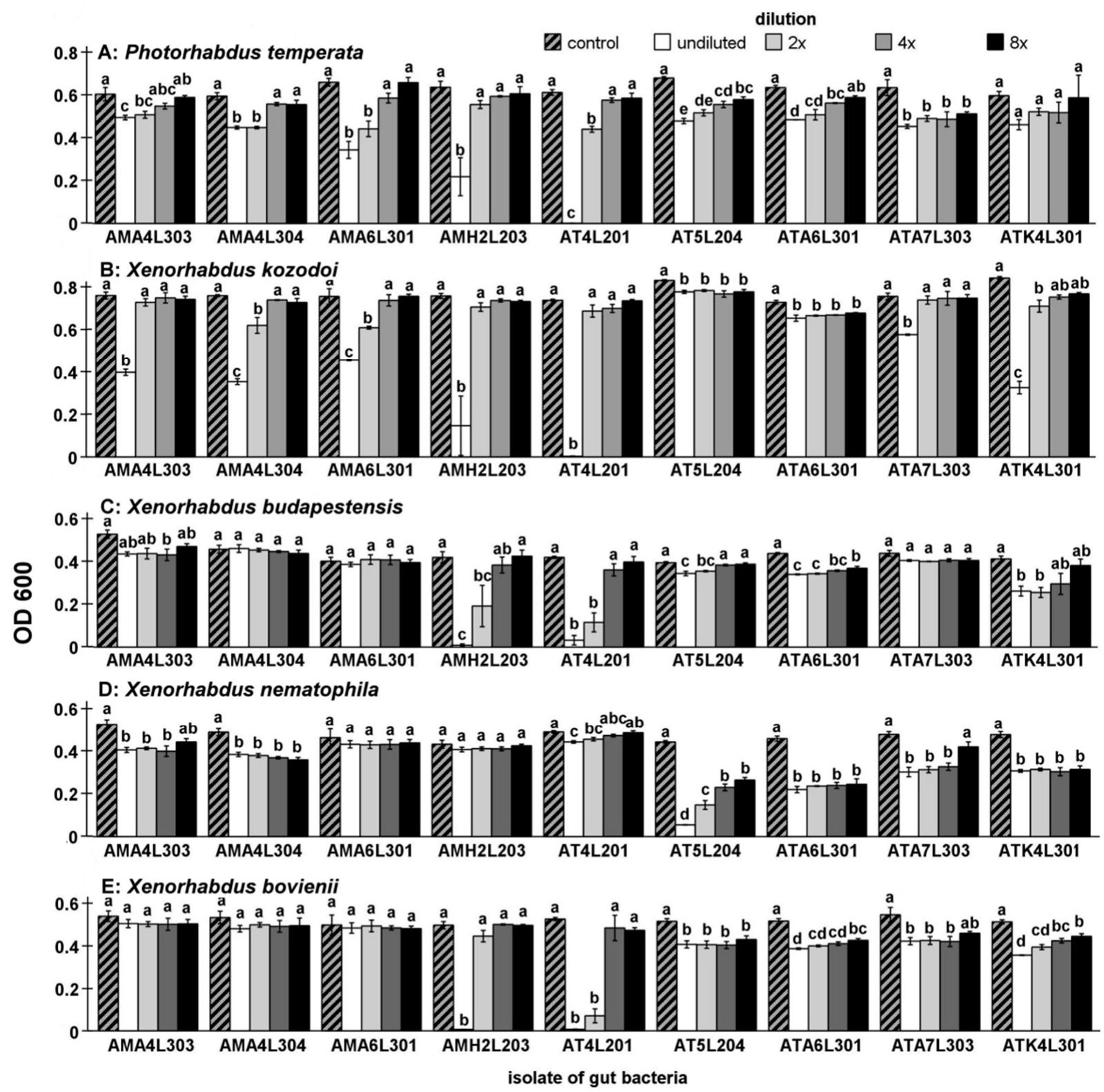

Figure 2. Differences in the antibacterial activities of increasing dilutions of supernatants from selected A. solstitiale gut isolates against P. temperata (A), X. kozodoi (B), X. budapestensis (C), X. nematophila (D) and X. bovienii (E) in the MID tests. The same letters above bars in the group mean no statistically significant differences between the inhibitory activity of supernatants.

\subsection{Molecular Identification of Isolates}

All isolates showing the ability to limit the growth of EPN microsymbionts in the cross-streak experiments were taxonomically identified with the use of gene sequence analysis. The first step of molecular identification was based on $16 \mathrm{~S}$ rDNA sequencing. Almost full-length sequences of the 16S rRNA gene were determined by PCR performed with the use of universal primers. Subsequently, the $r p o B$ or gap $A$ gene sequences were determined using primers specific to a given genus (Table 2). 
Table 2. Oligonucleotides used in the study.

\begin{tabular}{|c|c|c|c|c|c|c|}
\hline Primer & Sequence & $\begin{array}{l}\text { Target } \\
\text { Gene }\end{array}$ & $\begin{array}{l}\text { Target } \\
\text { Bacterial } \\
\text { Genus }\end{array}$ & $\begin{array}{l}\text { PCR } \\
\text { Cycling }\end{array}$ & $\begin{array}{l}\text { Product } \\
\text { Length }\end{array}$ & Reference \\
\hline $\begin{array}{l}27 \mathrm{~F} \\
1492 \mathrm{R}\end{array}$ & $\begin{array}{l}\text { 5'-AGAGTTTGATCCTGGCTCAG-3' } \\
\text { 5'-GGTTACCTTGTTACGACTT-3' }^{\prime}\end{array}$ & $\begin{array}{l}\text { 16S } \\
\text { rDNA }\end{array}$ & All tested & $\begin{array}{c}3 \min 95^{\circ} \mathrm{C}, 30 \times \\
\left(30 \mathrm{~s} 94^{\circ} \mathrm{C}, 45 \mathrm{~s}\right. \\
\left.55^{\circ} \mathrm{C}, 90 \mathrm{~s} 72^{\circ} \mathrm{C}\right) \\
5 \min 72^{\circ} \mathrm{C}\end{array}$ & $1500 \mathrm{bp}$ & [12] \\
\hline $\begin{array}{c}\text { rpoB1206 } \\
\text { rpoBR3202 }\end{array}$ & $\begin{array}{c}\text { 5- } \\
\text { 'ATCGAAACGCTGAAGGTCCAAACAT- } \\
3^{\prime} \\
\text { 5'-ACACCCTTGTTACCGTGACGACC-3' }\end{array}$ & rров & Bacillus & $\begin{array}{l}3 \min 95^{\circ} \mathrm{C}, 35 \times \\
\left(20 \mathrm{~s} 94^{\circ} \mathrm{C}, 30 \mathrm{~s}\right. \\
\left.55^{\circ} \mathrm{C}, 90 \mathrm{~s} 72^{\circ} \mathrm{C}\right) \\
5 \min 72^{\circ} \mathrm{C}\end{array}$ & $1170 \mathrm{bp}$ & [13] \\
\hline $\begin{array}{l}\text { ESbre-rpoF } \\
\text { ESbre-rpoR }\end{array}$ & $\begin{array}{l}\text { 5'-GTTTTGGACCTTCCGAATCTGA-3' } \\
\text { 5'-TGGGCGTAGACGCTCATAGAT-3' }\end{array}$ & rров & $\begin{array}{c}\text { Bacillus } \\
\text { [Brevibacterium] }\end{array}$ & $\begin{array}{c}3 \min 95{ }^{\circ} \mathrm{C}, 30 \times \\
\left(60 \mathrm{~s} 94{ }^{\circ} \mathrm{C}, 30 \mathrm{~s}\right. \\
\left.50^{\circ} \mathrm{C}, 60 \mathrm{~s} 722^{\circ} \mathrm{C}\right) \\
5 \mathrm{~min} 72^{\circ} \mathrm{C}\end{array}$ & 660 bp & This work \\
\hline $\begin{array}{l}\text { ESchr-rpoF } \\
\text { ESchr-rpoR }\end{array}$ & 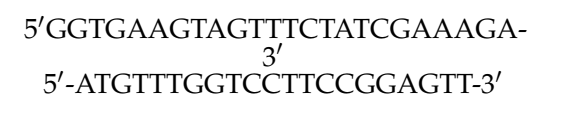 & rров & Chryseobacterium & $\begin{array}{c}3 \min 95^{\circ} \mathrm{C}, 30 \times \\
\left(35 \mathrm{~s} 95^{\circ} \mathrm{C}, 35 \mathrm{~s}\right. \\
\left.52^{\circ} \mathrm{C}, 50 \mathrm{~s} 722^{\circ} \mathrm{C}\right) \\
5 \mathrm{~min} 72^{\circ} \mathrm{C}\end{array}$ & 790 bp & This work \\
\hline $\begin{array}{l}\text { Vic3 } \\
\text { Vic2 }\end{array}$ & $\begin{array}{l}\text { 5'-GGCGAAATGGCWGAGAACCA-3' } \\
\text { 5'-GAGTCTTCGAAGTTGTAACC-3' }\end{array}$ & rров & Citrobacter & $\begin{array}{c}4 \min 94{ }^{\circ} \mathrm{C}, 30 \times \\
\left(30 \mathrm{~s} 94{ }^{\circ} \mathrm{C}, 30 \mathrm{~s}\right. \\
\left.50^{\circ} \mathrm{C}, 45 \mathrm{~s} 72^{\circ} \mathrm{C}\right) \\
5 \min 72^{\circ} \mathrm{C}\end{array}$ & 410 bp & [14] \\
\hline $\begin{array}{l}\text { ESent-rpoF } \\
\text { ESent-rpoR }\end{array}$ & $\begin{array}{l}\text { 5'-AACGAAGGTGTTGTTGAATTCGT-3' } \\
\text { 5'-CGAAACGTTGTCCACCAAATTG-3' }\end{array}$ & rров & Enterococcus & $\begin{array}{c}3 \min 95^{\circ} \mathrm{C}, 30 \times \\
\left(60 \mathrm{~s} 94^{\circ} \mathrm{C}, 30 \mathrm{~s}\right. \\
\left.50^{\circ} \mathrm{C}, 60 \mathrm{~s} 72^{\circ} \mathrm{C}\right) \\
5 \min 72^{\circ} \mathrm{C}\end{array}$ & $1170 \mathrm{bp}$ & This work \\
\hline $\begin{array}{l}\text { F1 } \\
\text { R1 }\end{array}$ & $\begin{array}{c}5^{\prime}- \\
\text { GTDAAARTDGGTATAACGGHTTYGG- } \\
3^{\prime} \\
5^{\prime}- \\
\text { TTGTCRTACCARGMWAYRRYTTTHACCA- } \\
3^{\prime}\end{array}$ & gapA & Paenibacillus & $\begin{array}{l}3 \min 95^{\circ} \mathrm{C}, 30 \times \\
30 \mathrm{~s} 95^{\circ} \mathrm{C}, 30 \mathrm{~s} 55 \\
\left.{ }^{\circ} \mathrm{C}, 50 \mathrm{~s} 72^{\circ} \mathrm{C}\right), 5 \\
\min 72^{\circ} \mathrm{C}\end{array}$ & 900 bp & [15] \\
\hline $\begin{array}{l}359 \mathrm{f} \\
359 \mathrm{r}\end{array}$ & $\begin{array}{l}\text { 5'-TTATCGCTCAGGCGAACTCCAAC-3' } \\
\text { 5'-TGCTGGATTCGCCTTTGCTACG-3' }\end{array}$ & rpoB & Serratia & $\begin{array}{c}3 \min 95^{\circ} \mathrm{C}, 30 \times \\
\left(50 \mathrm{~s} 94^{\circ} \mathrm{C}, 40 \mathrm{~s}\right. \\
\left.52^{\circ} \mathrm{C}, 60 \mathrm{~s} 72^{\circ} \mathrm{C}\right) \\
5 \min 72^{\circ} \mathrm{C}\end{array}$ & 530 bp & [16] \\
\hline
\end{tabular}

The $16 \mathrm{~S}$ rRNA threshold values of $95 \%$ and $98.7 \%$ gene sequence similarity between the tested isolate and the reference strain were used as indicators that an isolate represented a certain genus or species, respectively. The affiliation of an isolate to the given species was considered finished when the 16S rRNA gene sequence analysis were in agreement with those based on the rpoB or gapA sequencing. As shown in Table 3, the strains shared very high $16 \mathrm{~S}$ rRNA gene sequence similarity $(98.4-100 \%)$ to some type strain sequences deposited in GenBank, indicating that they represented genera Bacillus (7 isolates), Chryseobacterium (6 isolates), Citrobacter (2 isolates), Enterococcus (2 isolates), Serratia (2 isolates), and Paenibacillus (1 isolate). Then, on the basis of the rpoB or gapA sequence identity values, we identified 4 isolates as Chryseobacterium lathyri, 3 isolates as Bacillus wiedmannii, 2 isolates as Bacillus toyonensis, 2 isolates as Bacillus [Brevibacterium] frigoritolerans, 2 isolates as Enterococcus malodoratus, 2 isolates as Citrobacter murliniae, and 1 isolate as Serratia marcescens. These identification results were finally confirmed by phylogenetic analysis based on $16 \mathrm{~S} \mathrm{rDNA}$, and rpoB or gap $A$ markers, demonstrating close relationships of the tested analyzed isolates with the reference strains reflected in formation of well separated branches with high bootstrap values. Only 4 isolates could not be assigned to the species level, as they were clearly separated from the recognized species (Supplementary Data Figures S1-S3). 
Table 3. Molecular identification of bacterial strains with antimicrobial activity isolated from the midgut of A. solstitiale larvae.

\begin{tabular}{|c|c|c|c|}
\hline \multirow[t]{2}{*}{ Strain ID } & \multirow[t]{2}{*}{$\begin{array}{l}\text { Identification Result/Gene } \\
\text { Accession Numbers }\end{array}$} & \multicolumn{2}{|c|}{$\begin{array}{c}\text { Strain with the Highest Similarity to the Isolate in the } \\
\text { Gene Bank Based on the Gene Sequence/Gene Accession } \\
\text { Number/\% Nucleotide Identity }\end{array}$} \\
\hline & & 16S rDNA & rpoD/Gap * \\
\hline AT4 L2 01 & $\begin{array}{l}\text { Citrobacter murliniae } \\
\text { 16S rDNA-MW468102 } \\
\text { rpoB-MW481653 }\end{array}$ & $\begin{array}{c}\text { C. braaki ATCC 51113 } \\
\text { (NAEW01000064) 99.6\% } \\
\text { C. europeus 97/99 } \\
\text { (FLYB01000015) 99.6\% } \\
\text { C. murliniae CDC 2970-59T } \\
\text { (AF025369) 99.6\% }\end{array}$ & $\begin{array}{l}\text { C. murliniae CIP } 104556^{\mathrm{T}} \\
\text { (KM516007) } 99.7 \% \\
\text { C. braakii CIP } 104554^{\mathrm{T}} \\
\text { (KF057930) } 96.5 \%\end{array}$ \\
\hline AT5 L2 01 & $\begin{array}{l}\text { Bacillus toyonensis } \\
\text { 16S rDNA-MW467541 } \\
\text { rpoB-MW481644 }\end{array}$ & $\begin{array}{l}\text { B. mobilis 0711P9- } 1^{\mathrm{T}} \\
\text { (KJ812449) } 100 \% \\
\text { B. thuringensis ATCC } 10792^{\mathrm{T}} \\
\text { (ACNF01000156) } 100 \% \text { B. toyonensis BCT-712 } \\
\text { (CP006863) } 99.9 \%\end{array}$ & $\begin{array}{l}\text { B. toyonensis BCT-7112 } \\
\text { (NC_022781) 99.3\% } \\
\text { B. mobilis 0711P9 } \\
\text { (NZ_MACH01000024) } \\
98.8 \%\end{array}$ \\
\hline AT5 L2 02 & $\begin{array}{l}\text { Enterococcus } \\
\text { malodoratus } \\
16 \mathrm{~S} \text { rDNA-MW468100 } \\
\text { rpoB-MW481650 }\end{array}$ & $\begin{array}{l}\text { E. malodoratus ATCC 43197T } \\
\text { (ASWA01000002) 99.8\% } \\
\text { E. gilvus ATCC BAA-350T } \\
\text { (AJDQ01000009) 99.7\% }\end{array}$ & $\begin{array}{l}\text { E. malodoratus ATCC } 43197^{\mathrm{T}} \\
\text { (HQ611251) 99.2\% } \\
\text { E. gilvus ATCC BAA-350 } \\
\text { (HQ611245) 90.7\% }\end{array}$ \\
\hline AT5 L2 04 & $\begin{array}{c}\text { Enterococcus } \\
\text { malodoratus } \\
\text { 16S rDNA-MW468101 } \\
\text { rpoB-MW481651 }\end{array}$ & $\begin{array}{l}\text { E. malodoratus ATCC } 43197^{\mathrm{T}} \\
\text { (ASWA01000002) } 99.8 \% \\
\text { E. gilvus ATCC BAA-350 } \\
\text { (AJDQ01000009) } 99.7 \%\end{array}$ & $\begin{array}{l}\text { E. malodoratus ATCC } 43197^{\mathrm{T}} \\
\text { (HQ611251) 99.2\% } \\
\text { E. gilvus ATCC BAA-350 } \\
\text { (HQ611245) } 90.7 \%\end{array}$ \\
\hline ATA3 L3 05 & $\begin{array}{l}\text { Citrobacter murliniae } \\
\text { 16S rDNA } \\
\text { rpoB-MW557598 }\end{array}$ & $\begin{array}{c}\text { C. braaki ATCC 51113 } \\
\text { (NAEW01000064) 99.6\% } \\
\text { C. europeus 97/99T } \\
\text { (FLYB01000015) 99.6\% } \\
\text { C. murliniae CDC 2970-59T } \\
\text { (AF025369) 99.6\% }\end{array}$ & $\begin{array}{l}\text { C. murliniae CIP } 104556^{\mathrm{T}} \\
\text { (KM516007) } 99.7 \% \\
\text { C. braakii CIP } 104554^{\mathrm{T}} \\
\text { (KF057930) } 96.5 \%\end{array}$ \\
\hline ATA6 L3 01 & $\begin{array}{l}\text { Bacillus wiedmannii } \\
\text { 16S rDNA-MW467540 } \\
\text { rpoB-MW481647 }\end{array}$ & $\begin{array}{c}\text { B. wiedmannii FSL W80169 } \\
\text { (KU198626) 99.9\% } \\
\text { B. proteolitycus TD42 } \\
\text { (MACH0000033) } 99.8 \%\end{array}$ & $\begin{array}{l}\text { B. wiedmannii FSL W80169 } \\
\text { (LOBC01000027) } 99.4 \% \\
\text { B. proteolitycus TD42 } \\
\text { (NZ_MACH01000136) } \\
96.0 \%\end{array}$ \\
\hline ATA6 L3 02 & $\begin{array}{l}\text { Chryseobacterium sp. } \\
\text { 16S rDNA-MM429323 } \\
\text { rpoB-MN445060 }\end{array}$ & $\begin{array}{l}\text { C. viscerum 687B-08 } \\
\text { (FR871426) } 98.6 \% \\
\text { C. tructae 1084-08 } \\
\text { (FR871429) } 98.4 \%\end{array}$ & $\begin{array}{c}\text { C. jejuense DSM 19299 } \\
\text { (JX293153) 96.8\% } \\
\text { C. nakagawai NCTC13529T } \\
96.6 \% \\
\text { C. viscerum 687B-08 }{ }^{\mathrm{T}} \\
\text { (PEG02000009) 95.6\% }\end{array}$ \\
\hline ATA7 L3 01 & $\begin{array}{l}\text { Bacillus wiedmanniii } \\
\text { 16S rDNA-MW467539 } \\
\text { rpoB-MW481646 }\end{array}$ & $\begin{array}{c}\text { B. proteolitycus TD42 } 2^{\mathrm{T}} \\
\text { (MACH0000033) } 100 \% \\
\text { B. toyonensis BCT-7112 } \\
\text { (CP006863) } 100 \% \\
\text { B. wiedmannii FSL W8-0169 } \\
\text { (KU198626) } 99.9 \%\end{array}$ & $\begin{array}{l}\text { B. wiedmannii FSL W80169 } \\
\text { (LOBC01000027) } 99.4 \% \\
\text { B. toyonensis BCT-7112 } \\
\text { (NC_022781) } 96.8 \% \\
\text { B. proteolitycus TD42 } \\
\text { (NZ_MACH01000136) } \\
96.0 \%\end{array}$ \\
\hline ATA7 L3 02 & $\begin{array}{c}\text { Chryseobacterium } \\
\text { lathyri } \\
\text { 16S rDNA-MM429324 } \\
\text { rpoB-MN445061 }\end{array}$ & $\begin{array}{l}\text { C. lathyri RBA2-6 } \\
\text { (DQ673674) } 99.8 \%\end{array}$ & $\begin{array}{c}\text { C. lathyri KCTC 22544 } \\
\text { (NZ_QNFY01000004) 99.1\% }\end{array}$ \\
\hline ATA7 L3 03 & $\begin{array}{l}\text { Serratia sp. } \\
\text { 16S rDNA-MM422008 } \\
\text { rpoB-MN445054 }\end{array}$ & $\begin{array}{l}\text { S. plymuthica DSM 4540 } \\
\text { (AJ233433) } 99.6 \%\end{array}$ & $\begin{array}{l}\text { Serratia quinivorans LMG } \\
7887^{\mathrm{T}} \text { (JX425320) } 98.3 \% \\
\text { Serratia plymuthica LMG } \\
7886^{\mathrm{T}} \text { (JX425330) } 98.1 \%\end{array}$ \\
\hline
\end{tabular}


Table 3. Cont.

\begin{tabular}{|c|c|c|c|}
\hline \multirow[t]{2}{*}{ Strain ID } & \multirow[t]{2}{*}{$\begin{array}{l}\text { Identification Result/Gene } \\
\text { Accession Numbers }\end{array}$} & \multicolumn{2}{|c|}{$\begin{array}{c}\text { Strain with the Highest Similarity to the Isolate in the Gene } \\
\text { Bank Based on the Gene Sequence/Gene Accession } \\
\text { Number/\% Nucleotide Identity }\end{array}$} \\
\hline & & 16S rDNA & rpoD/Gap * \\
\hline ATA7 L3 04 & $\begin{array}{l}\text { Chryseobacterium } \\
\text { lathyri } \\
\text { 16S rDNA-MM429320 } \\
\text { rpoB-MN445062 }\end{array}$ & $\begin{array}{l}\text { C. lathyri RBA2-6 } \text { (DQ673674) }^{\mathrm{T}} \\
99.8 \%\end{array}$ & $\begin{array}{c}\text { C. lathyri KCTC 22544 } \\
\text { (NZ_QNFY01000004) } 98.4\end{array}$ \\
\hline AMA4 L3 03 & $\begin{array}{l}\text { Chryseobacterium } \\
\text { lathyri } \\
\text { 16S rDNA-MM429319 } \\
\text { rpoB-MN445053 }\end{array}$ & $\begin{array}{l}\text { C. lathyri RBA2-6 } 6^{\mathrm{T}} \text { (DQ673674) } \\
99.4 \%\end{array}$ & $\begin{array}{c}\text { C. lathyri KCTC 22544 } \\
\text { (NZ_QNFY01000004) } 98.6 \%\end{array}$ \\
\hline AMA4 L3 04 & $\begin{array}{l}\text { Chryseobacterium } \\
\text { lathyri } \\
\text { 16S rDNA-MM429321 } \\
\text { rpoB-MN445057 }\end{array}$ & $\begin{array}{l}\text { C. lathyri RBA2-6 } \text { (DQ673674) }^{\mathrm{T}} \\
99.2 \%\end{array}$ & $\begin{array}{c}\text { C. lathyri KCTC 22544 } \\
\text { (NZ_QNFY01000004) } 98.6 \%\end{array}$ \\
\hline AMA6 L3 01 & $\begin{array}{l}\text { Chryseobacterium sp. } \\
\text { 16S rDNA-MM429322 } \\
\text { rpoB-MN445059 }\end{array}$ & $\begin{array}{c}\text { C. viscerum } 687 \mathrm{~B}-08^{\mathrm{T}} \\
\text { (FR871426) } 98.7 \% \\
\text { C. tructae } 1084-08^{\mathrm{T}}(\mathrm{FR} 871429) \\
98.5 \%\end{array}$ & $\begin{array}{c}\text { C. jejuense DSM 19299 } \\
\text { (JX293153) 96.8\% } \\
\text { C. nakagawai NCTC13529 } \\
\text { (LR134386) 96.4\% } \\
\text { C. viscerum 687B-08 } \\
\text { (PEG02000009) } 95.4 \%\end{array}$ \\
\hline AMA7 L3 01 & $\begin{array}{l}\text { Bacillus wiedmanniii } \\
\text { 16S rDNA-MW467543 } \\
\text { rpoB-MW481643 }\end{array}$ & $\begin{array}{c}\text { B. mobilis 0711P9 } \text { (KJ812449) }^{\mathrm{T}} \text { (K9.7\% } \\
\text { B. toyonensis BCT-7112 } \\
\text { (CP006863) } 99.7 \% \\
\text { B. wiedmannii FSL W80169 } \\
\text { (KU198626) } 99.6 \%\end{array}$ & $\begin{array}{l}\text { B. wiedmannii FSL W80169 } \\
\text { (LOBC01000027) } 99.7 \% \\
\text { B. mobilis 0711P9 } \\
\text { (NZ_MACH01000024) } 99.1 \% \\
\text { B. toyonensis BCT-7112 } \\
\text { (NC_022781) } 97.0 \%\end{array}$ \\
\hline ATK3 L3 01 & $\begin{array}{c}\text { Bacillus } \\
\text { [Brevibacterium] } \\
\text { frigoritolerans } \\
\text { 16S rDNA-MW467545 } \\
\text { rpoB-MW481648 }\end{array}$ & $\begin{array}{l}\text { B. frigoritolerans DSM } 8801^{\mathrm{T}} \\
\text { (AM747813) } 99.5 \% \\
\text { B. simplex NBRC } 15720^{\mathrm{T}} \\
\text { (NR_042136) } 99.1 \%\end{array}$ & $\begin{array}{l}\text { B. frigoritotolerans FJAT-2396 } \\
\text { (NZ_KV440950) } 98.3 \% \\
\text { B. simplex DSM } 1321^{\mathrm{T}} \\
\text { (CP017704) } 96.8 \%\end{array}$ \\
\hline ATK4 L3 01 & $\begin{array}{c}\text { Bacillus } \\
\text { [Brevibacterium] } \\
\text { frigoritolerans } \\
\text { 16S rDNA-MW467544 } \\
\text { rpoB-MW481649 }\end{array}$ & $\begin{array}{l}\text { B. frigoritolerans DSM } 8801^{\mathrm{T}} \\
\text { (AM747813) } 99.5 \% \\
\text { B. simplex NBRC } 15720^{\mathrm{T}} \\
\text { (DSM1321T) } 99.2 \%\end{array}$ & $\begin{array}{l}\text { B. frigoritotolerans FJAT-2396 }{ }^{\mathrm{T}} \\
\text { (NZ_KV440950) 98.3\% } \\
\text { B. simplex DSM1321 } 96.8 \% \\
\text { (CP017704) }\end{array}$ \\
\hline AMK6 L3 01 & $\begin{array}{l}\text { Bacillus toyonensis } \\
\text { 16S rDNA-MW467542 } \\
\text { rpoB-MW481645 }\end{array}$ & $\begin{array}{c}\text { B. mobilis } 0711 \mathrm{P9}^{\mathrm{T}}(\mathrm{KJ} 812449) \\
99.7 \% \\
\text { B. toyonensis BCT-712 } \\
\text { (CP006863) } 99.5 \%\end{array}$ & $\begin{array}{l}\text { B. toyonensis BCT-7112 } \\
\text { (NC_022781) } 100 \% \\
\text { B. mobilis 0711P9 } \\
\text { (NZ_MACH01000024) } 97.5 \%\end{array}$ \\
\hline ATH3 L2 10 & $\begin{array}{l}\text { Serratia marcescens } \\
\text { 16S rDNA-MW468103 } \\
\text { rpoB-MW481652 }\end{array}$ & $\begin{array}{c}\text { S. marcescens subsp. marcescens } \\
\text { ATCC } 13880^{\mathrm{T}} \text { (IMPQ01000005) } \\
99.6 \%\end{array}$ & $\begin{array}{c}\text { S. marcescens subsp. marcescens } \\
\text { ATCC } 13880^{\mathrm{T}} \text { (CP041233) } \\
97.3 \%\end{array}$ \\
\hline AMH2 L2 03 & $\begin{array}{c}\text { Paenibacillus sp. } \\
\text { 16S rDNA-MW468104 } \\
\text { gap- MW481654 }\end{array}$ & $\begin{array}{l}\text { P. peoriae DSM } 8320^{\mathrm{T}} \\
\text { (AJ320494) } 99.8 \% \\
\text { P. jamilae KACC } 10925^{\mathrm{T}} \\
\text { (QVP01000089) } 99.6 \% \\
\text { P. polymyxa ATCC } 842^{\mathrm{T}} \\
\text { (AFOX01000032) } 99.4 \%\end{array}$ & $\begin{array}{c}\text { P. jamilae KACC } 10925^{\mathrm{T}} \\
\text { (NZ_QVPU01000020) } 95.9 \% \\
\text { P. cribbensis AM49 } \\
\text { (CP020028) } 95.8 \% \\
\text { P. peoriae KCTC } 3763^{\mathrm{T}} \\
\text { (NZ_AGFX01000038) } 94.5 \%\end{array}$ \\
\hline
\end{tabular}

\footnotetext{
* The rpoB gene was analyzed for all strains mentioned, except Peanibacillus sp., for which the gapA gene was analyzed.
} 


\section{Discussion}

A comparison of the data presented in Table 1 and Figure 2 shows that the majority of the A. solstitiale midgut isolates capable of inhibiting EPN bacteria growth in the cross-tests did not exhibit such potential in the MID tests. The post-culture filtrates of only 9 of the 20 isolates indicated by the cross-tests had antimicrobial activity against the selected nematode symbionts. Similar results were presented in our previous study, where midgut bacteria were isolated from M. melolontha. Only 7 of the 38 isolates selected with the use of the cross-tests exhibited antimicrobial activity in the MID tests [17]. Probably, the antagonistic activity of some midgut isolates against EPN symbionts is induced by direct contact with these bacteria. Hence, in the absence of such contact in the MID tests, no EPN bacteria growth inhibition was observed in many cases. Noteworthy, the strains with the highest antimicrobial activity in the MID tests (AT4 L2 01 and AMH2 L2 03) did not exhibit the highest level of this activity in the cross-tests. Based on the results of the investigations of bacteria colonizing the midguts of $A$. solstitiale and M. melolontha larvae, it can be concluded that cross-tests seem to be a simple and effective method for screening insect midgut strains capable of inhibiting EPN bacteria growth, whereas MID tests have quite limited application in this case. The agar well diffusion tests and agar disk diffusion tests, whose suitability was checked in our research, failed as well. In the vast majority of cases, these tests showed no antimicrobial activity of the tested isolates, probably for the same reason as in the case of the MID tests.

The genotyping approach based on 16S rRNA gene is helpful for taxonomic identification of bacterial isolates, especially as there are currently accepted sequence similarity threshold values available established at $98.65 \%$ and $95 \%$ for species and genus delineation, respectively [18-20]. However, the $16 \mathrm{~S}$ rRNA gene is not recommended as the only molecular marker for effective differentiation of bacterial species, as high conservation, recombination events, and horizontal gene transfer of rRNA genes may lead to misinterpretation in species classification [21-23]. Therefore, comparable sequence analysis of $16 \mathrm{~S}$ rRNA verified by analysis of single housekeeping gene sequences have been used in many studies for fast, relatively cheap, and reliable identification of bacteria derived from diverse environments $[13,24,25]$. The chosen housekeeping gene should meet the criteria of a single copy in the genome, high discriminatory power, and no proneness to recombination and lateral gene transfer [26]. By sequencing the $16 \mathrm{~S}$ rRNA together with rpoB or gapA, which are molecular markers with proven effectiveness $[15,25,27]$, we were able to provide an accurate species identification for 16 of the 20 isolates. The other 4 isolates were attributed to a certain genus, potentially representing new species.

The most numerous isolates were representatives of the genera Bacillus and Chryseobacterium. Bacillus spp. have been isolated from the alimentary tract of many Scarabaeidae species. They were isolated e.g., from the midgut of Melolontha hippocastani larvae [28]. The presence of Bacillus licheniformis exhibiting cellulase activity was detected in hindguts of Holotrichia parallela larvae [29]. Cellulose-decomposing Bacillus bacteria were also isolated from the midgut of unidentified Scarabaeidae larvae collected in the tropical forests of Costa Rica [30]. The presence of Bacillus bacteria was also detected in the midguts of non-scarab beetles, e.g., Dendroctonus armandi [31], Agrilus planipennis [32], and Poecilus chalcites [33]. One of the strains described in this study, Bacillus toyonensis, together with several insect-pathogen bacterial species, such as Bacillus cereus, Bacillus anthracis, and Bacillus thuringiensis, are included in the "Bacillus cereus group", i.e., a group of species with closely related phylogeny [34]. Two other isolates were identified as B. wiedmannii, a species that is also closely related to this group of bacilli; hence, it has been proposed that they should be included in this group [35]. Some members of this group, e.g., $B$. thuringiensis and B. cereus, are well known pathogens of insects. They enter the organism via the alimentary system, i.e., they are temporarily present in the midgut. $B$. thuringiensis was isolated from M. melolontha larvae [36,37], while B. cereus was detected in A. solstitiale larvae [38]. However, no pathogenicity of B. toyonensis or B. wiedmannii against insects has been reported to date. In addition to the bacteria from the genus Bacillus, one of the 
isolates was identified as a representative of the phylogenetically close genus Paenibacillus. P. popilliae, which is a known insect pathogen, has been repeatedly detected in Scarabaeidae larvae, e.g., in the hemolymph of Amphimallon solstitiale [39] and Popillia japonica [40].

Bacteria of the genus Chryseobacterium have quite often been found in the organisms of beetles, e.g., in the midgut of Protaetia brevitarsis [41], D. armandi [31], and A. planipennis [32]. In contrast to Bacillus and Paenibacillus bacteria, no pathogenicity of Chryseobacterium bacteria against Scarabaeidae larvae has been reported to date.

The next four isolates are representatives of the genera Citrobacter and Serratia from the order Enterobacterales. Citrobacter bacteria have been isolated from midguts of Scarabaeidae larvae, e.g., H. parallela [29] and Lepidiota mansueta [42]. The presence of Serratia bacteria has been detected in Scarabaeidae larvae as well. S. marcescens and S. liquefaciens have been isolated from the hemocoel of M. melolontha larvae [43]. Noteworthy, both bacterial species have been found to be pathogenic to Dendroctonus micans, Thaumetopoea pityocampa, and Lymantria dispar larvae. Serratia spp. have been isolated from midguts of M. hippocastani larvae [28] and Scarabaeidae larvae collected in Costa Rica [30].

The issue of the antagonistic activity of insect midgut microbiota against symbiotic bacteria of EPNs has been investigated to a very limited extent to date. Wollenberg et al. [44] isolated two Stenotrophomonas strains from cadavers of Galleria mellonella larvae that were previously infested with $H$. megidis. These bacteria were resistant to Photorhabdus-produced antibiotics and were able to inhibit the growth of some Photorhabdus strains. The obtained results suggested that the Stenotrophomonas species secreted a heat-stable molecule with inhibitory activity against Photorhabdus strains. More examples of the antagonistic activities of insect gut bacteria can be found in our previous study, in which we described some isolates from midguts of M. melolontha larvae capable of inhibiting the growth of EPN bacteria [17]. We identified 12 active isolates, half of which were Pseudomonas chlororaphis strains, and the others were classified as C. murliniae, Acinetobacter calcoaceticus, C. lathyri, Chryseobacterium sp., S. liquefaciens, and Serratia sp. As can be seen, the results of the previous study are partially consistent with the present report. C. murliniae, C. lathyri, and Serratia bacteria exhibiting antimicrobial activity against Xenorhabdus and Photorhabdus were isolated from the midguts of both $M$. melolontha and A. solstitiale. Taking into account the species richness of the midgut microbiota in Scarabaeidae larvae, the isolation of the same or related bacterial species in separate studies from larvae of two different insect species does not seem to be accidental. This probably indicates that these bacterial species or genera, compared to other bacteria inhabiting larval midguts, are more efficient in inhibition of the growth of pathogenic nematode symbionts and can be their natural antagonists. In addition to the bacterial species isolated from the midguts of both insect species, some bacteria were present in only one species. Especially interesting is the absence of $P$. chlororaphis among the isolates obtained from $A$. solstitiale, as the bacteria constituted a significant percentage of all active isolates from M. melolontha and its strains had the highest ability to inhibit Xenorhabdus and Photorhabdus growth. In turn, there were 7 strains representing the genus Bacillus among the active isolates obtained from $A$. solstitiale, while this genus was not detected among the M. melolontha isolates. However, this does not prove the specificity of bacteria exhibiting antagonistic properties against EPN bacterial symbionts in the midguts of larvae of the studied Scarabaeidae species. This was contradicted by our additional nanopore-sequencing studies of the midgut microbiota of $M$. melolontha and $S$. solstitilae larvae, but these results were only partially published [45]. The investigations demonstrated the presence of $B$. frigoritolerans in 17 of 31 studied midgut samples from $A$. solstitiale and 13 of 32 midgut samples from M. melolontha. B. wiedmannii was detected in 18 samples from $A$. solstitiale and 22 samples from $M$. melolontha. In turn, $B$. toyonensis was present in 16 samples from $A$. solstitiale and 15 samples from $M$. melolontha. Similarly, in the case of all other species isolated from $A$. solstitiale or $M$. melolontha midguts, showing antimicrobial activity against nematode bacterial symbionts, the metataxonomic studies showed their presence in both Scarabaeidae species (data not shown). The failure to isolate the same bacterial species from the midguts of both insects was most probably associated 
with the insufficient scale of our research, although it is also likely that not all bacterial strains of species identified in the presented study are capable of EPN bacteria growth inhibition.

Although some of the bacterial strains reported in this study had not been shown previously to exert an antagonistic effect on other bacterial species, such properties are not surprising in many cases. Bacillus spp. are known to produce a broad spectrum of antimicrobial substances, (peptide/lipopeptide antibiotics, bacteriocins) [46,47]. Culture extracts of $B$. toyonensis strain isolated from Folsomia candida gut had high inhibitory activity against Staphylococcus aureus, Pseudomonas syringae, Micrococcus luteus, and Bacillus subtilis. Genome analysis revealed several gene clusters coding the production of bacteriocins [48]. Similarly, Lopes et al. [49] sequenced the whole B. toyonensis BAC3151 genome and found that it had a higher frequency of putative bacteriocin gene clusters than that of Bacillus species used traditionally for production of antimicrobials. In turn, secondary metabolite extracts produced by B. toyonensis collected from sea waters inhibited the growth of Vibrio alginolyticus, Aeromonas hydrophila, and Pseudomonas aeruginosa [50].

Enterococcus bacteria are also well known to produce bacteriocins, referred to as enterocins in this case. Although no such antimicrobial peptides have been found in E. malodoratus to date, numerous enterocins have been detected in Enterococcus faecium, Enterococcus faecalis, or Enterococcus mundtii [51,52].

The greatest number of the active isolates obtained in this study was classified as the genus Chryseobacterium. Bacteria of this genus are not widely known for their antibacterial properties. Nevertheless, the antimicrobial properties of Chryseobacterium antibioticum against $P$. aeruginosa and Escherichia coli have been described [53], while bacteriocin gene clusters have been detected in Chryseobacterium indologenes [54].

Antibacterial activities have been described in the case of Serratia and Citrobacter bacteria as well. A S. marcescens strain originating from $M$. melolontha produced a bacteriocin-like substance with high activity against B. thuringiensis, B. cereus, Enterobacter sp., E. faecalis, Proteus mirabilis, Pseudomonas fluorescens, Staphylococcus cohni, Staphylococcus epidermidis, and many phytopathogenic bacteria [55]. Another S. marcescens strain was reported to produce bacteriocin $28 \mathrm{~b}$ with activity against E. coli [56]. In turn, S. marcescens strain ZPG19 produced prodigiosin, i.e., a bioactive secondary metabolite with antimicrobial effects [57]. In the case of Citrobacter bacteria, no antibacterial properties of $C$. murliniae have been described yet, while it has been reported that a bacteriocin from Citrobacter freundii is able to inhibita wide range of Gram-negative bacteria [58] and Citrobacter sp. produces antibacterial lipopeptides inhibiting $S$. aureus growth [59].

The study results show the presence of numerous bacterial strains in the midgut of $A$. solstitiale larvae with potential to inhibit the growth of Xenorhabdus or Photorhabdus bacteria introduced into the insect's organism by EPNs. Some of these strains have already been demonstrated to have antibacterial activity, although not against EPN bacteria. However, our study does not answer the key question whether the interactions also occur in vivo and may constitute one of the insect defense mechanisms. Elucidation of this issue would be highly important. It should also be noted that, although a relatively large number of midgut isolates were analyzed in our research (900 strains from $A$. solstitiale and 900 strains from $M$. melolontha isolated previously), many bacterial strains of interest have certainly not been detected. The selection procedures applied in the study allowed identification of only some bacterial species present in the larval midgut with a capability of strong antagonistic interactions against Xenorhabdus and Photorhabdus bacteria. Therefore, these fragmentary results require further comprehensive research to provide a complete picture of this problem.

\section{Materials and Methods}

\subsection{EPNs Culturing and Maintenance}

The study involved 5 EPN species isolated from soil sampled in Poland and identified using molecular methods. The nematodes were reproduced in G. mellonella (Lepidoptera: 
Pyralidae) larvae, grown on a natural diet and weighing 180-200 mg. Before use in the experiments, infective juveniles of EPNs were kept in a sterile aqueous solution at $8{ }^{\circ} \mathrm{C}$ for no longer than 15 days.

\subsection{EPN Bacterial Symbionts}

In this study 5 species of EPN symbionts were isolated and used: X. bovienii (host: S. kraussei), X. nematophila (host: S. carpocapsae), X. kozodoii (host: S. arenarium), X. budapestensis (host: S. bicornutum), and P. temperata (host: H. megidis). Cultures of the bacteria were suspended in lysogeny broth (LB) supplemented with $20 \%$ glycerol and placed at $-85^{\circ} \mathrm{C}$. Before use in the experiments thawed stock cultures of bacteria were tested on the NBTA plates to check the colony form. Only blue or green (primary form) colonies were used in subsequent analyses.

\subsection{Source of A. solstitiale Larvae}

The A. solstitiale larvae used in the study were collected in the Lublin region (East Poland). Larvae that were not subjected to nematode pressure and those exposed to $S$. arenarium, S. bicornutum, and P. temperata were found in grasslands located within the administrative boundaries of the city of Lublin, while the other larvae were collected in forest nursery plots located in Kozłowieckie Forests. The collected white grubs were placed separately in 50-mL plastic vessels with moist soil to protect the insects from stress (drying, biting). Only healthy L2 or L3 larvae were used in the experimental and control groups.

\subsection{Exposure of A. solstitiale to Selected EPN Species}

White grubs of $A$. solstitiale were placed individually on the bottom of $150-\mathrm{mL}$ vessels containing $100 \mathrm{~g}$ of moist ( - $50 \mathrm{kPa}$ water potential) soil originating from the harvesting field. Each insect larva was exposed to $~ 1000$ IJs of EPN. The cups with the scarab larvae were stored in incubators for 12 days at $20^{\circ} \mathrm{C}$.

\subsection{Isolation of Bacteria from A. solstitiale Midgut}

All larvae were surface sterilized using $70 \%$ alcohol and washed twice in sterile water. After drying for $1 \mathrm{~min}$, the digestive tract was dissected. Next, the midgut was homogenized in $1 \mathrm{~mL}$ of $0.5 \% \mathrm{NaCl}$ in a glass tissue grinder. Appropriate dilutions were spread on LB agar plates and incubated at $20^{\circ} \mathrm{C}$ for $2-4$ days in aerobic or microaerobic ( $6 \%$ oxygen) conditions. Single colonies were transferred to agar slants for further analyses.

\subsection{Antimicrobial Activity Assays}

The antimicrobial activity was evaluated by cross-streak tests and MID tests as described previously [17]. The only difference was the centrifugation parameters of the culture fluids used for the MID tests, which were as follows: $12,000 \mathrm{rpm}$ (about 10,000 $\times g$ ) for $15 \mathrm{~min}$.

\subsection{DNA Extraction and PCR}

The genomic DNA was isolated from 20 bacterial strains using a Genomic Mini AX Bacteria Spin Kit (A\&A Biotechnology, Gdynia, Poland) in accordance with the manufacturer instruction. All amplification reactions were carried out with FirePol Master Mix (Solis BioDyne, Tartu, Estonia). PCR amplifications of 2 molecular markers for each isolate, i.e., the $16 \mathrm{~S} r R N A$ gene and $r p o B$ (coding RNA polymerase subunit $\beta$ ) or gapA (coding glyceraldehyde- 3 phosphate dehydrogenase) were performed using primer pairs and PCR cycling parameters described in Table 2. Purifications of the amplicons were performed with the use of Clean-Up Kit (A\&A Biotechnology, Gdynia, Poland). The amplicons were sequenced using the same primers in Genomed S.A. (Warsaw, Poland). 


\subsection{Gene Sequencing and Phylogenetic Analysis}

The gene sequences of the isolates were analyzed using nucleotide BLAST (NCBI). Additionally, the 16S rRNA gene sequences were compared with those included in the EzBioCloude database [60]. The determined single gene sequences were aligned using ClustalW [61] implemented in the MEGA 6.06 software [62]. Sequence identity values were estimated using BioEdit 7.2 [63]. The phylograms were constructed using the neighborjoining (NJ) method [64] in the Maximum Composite Likelihood model in Mega 6.06. Bootstrap values for individual nodes demonstrating tree robustness were calculated for 1000 replicates [65].

The gene sequences obtained were submitted to the GenBank under accession numbers shown in Table 3 and on the phylogenetic trees (Figures S1-S3).

\subsection{Statistical Analysis}

As no statistically significant differences were found between the replicates of the experiments, the data were pooled together before statistical analysis. The normalcy of the data was checked by the Shapiro-Wilk test. The homogeneity of variance was assessed by the Levene test. MID tests results were subjected to one-way ANOVA. Means were separated with the Tukey HSD test. For pairwise comparisons (bacteria species) the tstudent test was used. Differences among the means were considered significant at $p<0.05$. All of the statistical analyses were performed using the SPSS Statistics 27 software package (IBM Corp., Armonk, NY, USA).

Supplementary Materials: The following are available online at https:/ /www.mdpi.com/article/10 .3390/ijms222112005/s1.

Author Contributions: Conceptualization, M.S., E.S. and A.W.; methodology, M.S., E.S., W.K. and M.L.; software, W.K. and M.L.; validation, M.S.; formal analysis, A.W.; investigation, M.S., E.S. and W.K.; resources, M.S., W.K. and M.L.; data curation, A.W. and M.L.; writing—original draft preparation, M.S.; writing—review and editing, M.S., E.S. and A.W.; visualization, M.L.; supervision, M.S. and E.S.; project administration, M.S. and A.W.; funding acquisition, M.S. and A.W. All authors have read and agreed to the published version of the manuscript.

Funding: This research was financially supported by the National Science Centre (Poland), grant number 2016/21/B/NZ9/01865.

Institutional Review Board Statement: Not applicable.

Informed Consent Statement: Not applicable.

Data Availability Statement: Not applicable.

Acknowledgments: The authors gratefully acknowledge use of the services and facilities of the Center for Interdisciplinary Research of The John Paul II Catholic University of Lublin, Lublin, Poland, co-funded by the European Union from the European Regional Development Fund in the frame of the Operational Programme Development of Eastern Poland 2007-2013 (POPW.01.03.00-06003/09-00).

Conflicts of Interest: The authors declare no conflict of interest.

\section{References}

1. Brivio, M.F.; Mastore, M. When appearance misleads: The role of the entomopathogen surface in the relationship with its host. Insects 2020, 11, 387. [CrossRef]

2. Castillo, J.; Reynolds, S.; Eleftherianos, I. Insect immune responses to nematode parasites. Trends Parasitol. 2011, $27,537-547$. [CrossRef] [PubMed]

3. Gulcu, B.; Cimen, H.; Raja, R.K.; Hazir, S. Entomopathogenic nematodes and their mutualistic bacteria: Their ecology and application as microbial control agents. Biopestic. Int. 2017, 13, 79-112.

4. Nielsen-LeRoux, C.; Gaudriault, S.; Ramarao, N.; Lereclus, D.; Givaudan, A. How the insect pathogen bacteria Bacillus thuringiensis and Xenorhabdus/Photorhabdus occupy their hosts. Curr. Opin. Microbiol. 2012, 15, 220-231. [CrossRef] [PubMed]

5. Hu, K.; Webster, J.M. Antibiotic production in relation to bacterial growth and nematode development in PhotorhabdusHeterorhabditis infected Galleria mellonella larvae. FEMS Microbiol. Lett. 2000, 189, 219-223. [CrossRef] 
6. Sharma, S.; Waterfield, N.; Bowen, D.; Rocheleau, T.; Holland, L.; James, R.; Ffrench-Constant, R. The lumicins: Novel bacteriocins from Photorhabdus luminescens with similarity to the uropathogenic-specific protein (USP) from uropathogenic Escherichia coli. FEMS Microbiol. Lett. 2002, 214, 241-249. [CrossRef]

7. Thaler, J.; Baghdiguian, S.; Boemare, N. Purification and characterization of xenorhabdicin, a phage tail-like bacteriocin, from the lysogenic strain F1 of Xenorhabdus nematophilus. Appl. Environ. Microbiol. 1995, 61, 2049-2052. [CrossRef] [PubMed]

8. Singh, S.; Reese, J.M.; Casanova-Torres, Á.M.; Goodrich-Blair, H.; Forst, S. Microbial population dynamics in the hemolymph of Manduca sexta infected with Xenorhabdus nematophila and the Entomopathogenic Nematode Steinernema carpocapsae. Appl. Environ. Microbiol. 2014, 80, 4277-4285. [CrossRef]

9. Silva, C.P.; Waterfield, N.R.; Daborn, P.J.; Dean, P.; Chilver, T.; Au, C.P.Y.; Sharma, S.; Potter, U.; Reynolds, S.E.; Ffrench-Constant, R.H. Bacterial infection of a model insect: Photorhabdus luminescens and Manduca sexta. Cell. Microbiol. 2002, 4, 329-339. [CrossRef]

10. Carneiro, C.N.; DaMatta, R.A.; Samuels, R.I.; Silva, C.P. Effects of entomopathogenic bacterium Photorhabdus temperata infection on the intestinal microbiota of the sugarcane stalk borer Diatraea saccharalis (Lepidoptera: Crambidae). J. Invertebr. Pathol. 2008, 99, 87-91. [CrossRef]

11. Sicard, M.; Brugirard-Ricaud, K.; Pagès, S.; Lanois, A.; Boemare, N.E.; Brehélin, M.; Givaudan, A. Stages of infection during the tripartite interaction between Xenorhabdus nematophila, its Nematode vector, and insect hosts. Appl. Environ. Microbiol. 2004, 70, 6473-6480. [CrossRef]

12. Miller, C.S.; Handley, K.M.; Wrighton, K.; Frischkorn, K.R.; Thomas, B.C.; Banfield, J. Short-read assembly of full-length 16s amplicons reveals bacterial diversity in subsurface sediments. PLoS ONE 2013, 8, e56018. [CrossRef] [PubMed]

13. Ki, J.-S.; Zhang, W.; Qian, P.-Y. Discovery of marine Bacillus species by $16 \mathrm{~S}$ rRNA and rpoB comparisons and their usefulness for species identification. J. Microbiol. Methods 2009, 77, 48-57. [CrossRef]

14. Delétoile, A.; Decré, D.; Courant, S.; Passet, V.; Audo, J.; Grimont, P.; Arlet, G.; Brisse, S. Phylogeny and identification of Pantoea species and typing of Pantoea agglomerans Strains by multilocus gene sequencing. J. Clin. Microbiol. 2009, 47, 300-310. [CrossRef] [PubMed]

15. Iiyama, K.; Nishi, O.; Mon, H.; Lee, J.M.; Kusakabe, T.; Asano, S.-I.; Yasunaga-Aoki, C.; Shimizu, S. Phylogenetic analysis of Paenibacillus popilliae and its related taxa based on housekeeping genes. J. Insect Biotechnol. Sericol. 2013, 82, 1-11. [CrossRef]

16. Whitehouse, C.A.; Baldwin, C.; Wasieloski, L.; Kondig, J.; Scherer, J. Molecular identification of the Biowarfare simulant Serratia marcescensfrom a 50-year-old munition buried at Fort Detrick, Maryland. Mil. Med. 2007, 172, 860-863. [CrossRef] [PubMed]

17. Skowronek, M.; Sajnaga, E.; Pleszczyńska, M.; Kazimierczak, W.; Lis, M.; Wiater, A. Bacteria from the midgut of common Cockchafer (Melolontha melolontha L.) Larvae exhibiting antagonistic activity against bacterial symbionts of Entomopathogenic Nematodes: Isolation and molecular identification. Int. J. Mol. Sci. 2020, 21, 580. [CrossRef] [PubMed]

18. Kim, M.; Oh, H.-S.; Park, S.-C.; Chun, J. Towards a taxonomic coherence between average nucleotide identity and 16S rRNA gene sequence similarity for species demarcation of prokaryotes. Int. J. Syst. Evol. Microbiol. 2014, 64, 346-351. [CrossRef]

19. Stackebrandt, E.; Ebers, J. Taxonomic parameters revised: Tarnished gold standards. Microbiol. Today 2006, 33, $152-155$.

20. Yarza, P.; Yilmaz, P.; Pruesse, E.; Glöckner, F.O.; Ludwig, W.; Schleifer, K.-H.; Whitman, W.; Euzéby, J.; Amann, R.; Rossello-Mora, R. Uniting the classification of cultured and uncultured bacteria and archaea using 16S rRNA gene sequences. Nat. Rev. Genet. 2014, 12, 635-645. [CrossRef]

21. Kitahara, K.; Miyazaki, K. Revisiting bacterial phylogeny. Mob. Genet. Elem. 2013, 3, e24210. [CrossRef]

22. Rossi-Tamisier, M.; Benamar, S.; Raoult, D.; Fournier, P.-E. Cautionary tale of using 16S rRNA gene sequence similarity values in identification of human-associated bacterial species. Int. J. Syst. Evol. Microbiol. 2015, 65, 1929-1934. [CrossRef]

23. Větrovský, T.; Baldrian, P. The variability of the $16 \mathrm{~S}$ rRNA gene in bacterial genomes and its consequences for bacterial community analyses. PLoS ONE 2013, 8, e57923. [CrossRef]

24. Sadeghi, P. Molecular methods for identification of Acinetobacter species by partial sequencing of the rpoB and $16 \mathrm{~S}$ rRNA genes. $J$. Clin. Diagn. Res. 2015, 9, DC09-DC13. [CrossRef]

25. Ogier, J.-C.; Pagès, S.; Galan, M.; Barret, M.; Gaudriault, S. rpoB, a promising marker for analyzing the diversity of bacterial communities by amplicon sequencing. BMC Microbiol. 2019, 19, 1-16. [CrossRef]

26. Glaeser, S.P.; Kämpfer, P. Multilocus sequence analysis (MLSA) in prokaryotic taxonomy. Syst. Appl. Microbiol. 2015, 38, 237-245. [CrossRef]

27. Adékambi, T.; Shinnick, T.M.; Raoult, D.; Drancourt, M. Complete rpoB gene sequencing as a suitable supplement to DNA-DNA hybridization for bacterial species and genus delineation. Int. J. Syst. Evol. Microbiol. 2008, 58, 1807-1814. [CrossRef]

28. Arias-Cordero, E.; Ping, L.; Reichwald, K.; Delb, H.; Platzer, M.; Boland, W. Comparative evaluation of the gut microbiota associated with the below- and above-ground life stages (larvae and beetles) of the forest cockchafer, Melolontha hippocastani. PLoS ONE 2012, 7, e51557. [CrossRef]

29. Huang, S.; Sheng, P.; Zhang, H. Isolation and identification of cellulolytic bacteria from the gut of Holotrichia parallela Larvae (Coleoptera: Scarabaeidae). Int. J. Mol. Sci. 2012, 13, 2563-2577. [CrossRef] [PubMed]

30. Rojas-Jiménez, K.; Hernández, M. Isolation of fungi and bacteria associated with the guts of tropical wood-feeding coleoptera and determination of their Lignocellulolytic Activities. Int. J. Microbiol. 2015, 2015, 285018. [CrossRef]

31. Wang, J.; Chen, H.; Tang, M. Community structure of gut bacteria of Dendroctonus armandi (Coleoptera: Curculionidae Scolytinae) larvae during overwintering stage. Sci. Rep. 2017, 7, 1-11. [CrossRef] [PubMed] 
32. Vasanthakumar, A.; Handelsman, J.; Schloss, P.D.; Bauer, L.S.; Raffa, K.F. Gut microbiota of an invasive subcortical beetle, Agrilus planipennis Fairmaire, across various life stages. Environ. Entomol. 2008, 37, 1344-1353. [CrossRef]

33. Lehman, R.M.; Lundgren, J.G.; Petzke, L.M. Bacterial communities associated with the digestive tract of the predatory ground beetle, Poecilus chalcites, and their modification by laboratory rearing and antibiotic treatment. Microb. Ecol. 2009, 57, 349-358. [CrossRef] [PubMed]

34. Ehling-Schulz, M.; Lereclus, D.; Koehler, T.M. The Bacillus cereus group: Bacillus species with pathogenic potential. Microbiol. Spectr. 2019, 7. [CrossRef]

35. Miller, R.A.; Beno, S.M.; Kent, D.J.; Carroll, L.; Martin, N.H.; Boor, K.; Kovac, J. Bacillus wiedmannii sp. nov., a psychrotolerant and cytotoxic Bacillus cereus group species isolated from dairy foods and dairy environments. Int. J. Syst. Evol. Microbiol. 2016, 66, 4744-4753. [CrossRef] [PubMed]

36. Sezen, K.; Demir, Ý.; Demirbağ, Z. Identification and pathogenicity of entomopathogenic bacteria from common cockchafer, Melolontha melolontha (Coleoptera: Scarabaeidae). N. Z. J. Crop Hortic. Sci. 2007, 35, 79-85. [CrossRef]

37. Kati, H.; Sezen, K.; Demirbağ, Z. Characterization of a highly pathogenic Bacillus thuringiensis strain isolated from common cockchafer, Melolontha melolontha. Folia Microbiol. 2007, 52, 146-152. [CrossRef] [PubMed]

38. Sezen, K.; Demir, I.; Kati, H.; Demirbag, Z. Investigations on bacteria as a potential biological control agent of summer chafer, Amphimallon solstitiale L. (Coleoptera: Scarabaeidae). J. Microbiol. 2005, 43, 463-468.

39. Glare, T.R.; Jackson, T.A.; Zimmermann, G. Occurrence of Bacillus popilliae and two nematode pathogens in populations of Amphimallon solstitialis (Col.: Scarabaeidae) near darmstadt, Germany. BioControl 1993, 38, 441-450. [CrossRef]

40. Cappaert, D.L.; Smitley, D.R. Parasitoids and pathogens of japanese beetle (Coleoptera: Scarabaeidae) in Southern Michigan. Environ. Èntomol. 2002, 31, 573-580. [CrossRef]

41. Tian, X.-Y.; Song, F.-P.; Zhang, J.; Liu, R.-M.; Zhang, X.-P.; Duan, J.-Y.; Shu, C.-L. Diversity of gut bacteria in larval Protaetia brevitarsis (Coleoptera: Scarabaedia) fed on corn stalk. Acta Entomol. Sin. 2017, 60, 632-641.

42. Handique, G.; Phukan, A.; Bhattacharyya, B.; Baruah, A.A.; Rahman, S.W.; Baruah, R. Characterization of cellulose degrading bacteria from the larval gut of the white grub beetle Lepidiota mansueta (Coleoptera: Scarabaeidae). Arch. Insect Biochem. Physiol. 2017, 94, e21370. [CrossRef]

43. Ertürk, Ö.; Yaman, M. Potential of five non-spore-forming bacteria, originated from the European cockchafer, Melolontha melolontha (Linnaeus, 1758) (Coleoptera: Scarabaeidae), on three economic insect pests. Egypt J. Biol. Pest Control 2019, 29, 1-5. [CrossRef]

44. Wollenberg, A.C.; Jagdish, T.; Slough, G.; Hoinville, M.E.; Wollenberg, M.S. Death becomes them: Bacterial community dynamics and stilbene antibiotic production in cadavers of Galleria mellonella killed by Heterorhabditis and Photorhabdus spp. Appl. Environ. Microbiol. 2016, 82, 5824-5837. [CrossRef] [PubMed]

45. Sajnaga, E.; Skowronek, M.; Kalwasińska, A.; Kazimierczak, W.; Ferenc, K.; Lis, M.; Wiater, A. Nanopore-sequencing characterization of the gut microbiota of Melolontha melolontha larvae: Contribution to protection against Entomopathogenic Nematodes? Pathogens 2021, 10, 396. [CrossRef]

46. Abriouel, H.; Franz, C.M.; Ben Omar, N.; Gálvez, A. Diversity and applications of Bacillus bacteriocins. FEMS Microbiol. Rev. 2011, 35, 201-232. [CrossRef]

47. Jeżewska-Frąckowiak, J.; Seroczyńska, K.; Banaszczyk, J.; Woźniak, D.; Żylicz-Stachula, A.; Skowron, P.M. The promises and risks of probiotic Bacillus species. Acta Biochim. Pol. 2018, 65, 509-519. [CrossRef]

48. Agamennone, V.; Van Straalen, J.; Brouwer, A.; De Boer, T.E.; Hensbergen, P.J.; Zaagman, N.; Braster, M.; Van Straalen, N.M.; Roelofs, D.; Janssens, T.K. Genome annotation and antimicrobial properties of Bacillus toyonensis VU-DES13, isolated from the Folsomia candidagut. Èntomol. Exp. Appl. 2019, 167, 269-285. [CrossRef]

49. Lopes, R.; Cerdeira, L.; Tavares, G.S.; Ruiz, J.C.; Blom, J.; Horácio, E.C.A.; Mantovani, H.C.; De Queiroz, M.V. Genome analysis reveals insights of the endophytic Bacillus toyonensis BAC3151 as a potentially novel agent for biocontrol of plant pathogens. World J. Microbiol. Biotechnol. 2017, 33, 185. [CrossRef]

50. Setiaji, J.; Feliatra, F.; Teruna, H.Y.; Lukistyowati, I.; Suharman, I.; Muchlisin, Z.A.; Johan, T.I. Antibacterial activity in secondary metabolite extracts of heterotrophic bacteria against Vibrio alginolyticus, Aeromonas hydrophila, and Pseudomonas aeruginosa. F1000Research 2020, 9, 1491. [CrossRef]

51. Franz, C.M.; Van Belkum, M.J.; Holzapfel, W.H.; Abriouel, H.; Galvez, A. Diversity of enterococcal bacteriocins and their grouping in a new classification scheme. FEMS Microbiol. Rev. 2007, 31, 293-310. [CrossRef] [PubMed]

52. Nes, I.F.; Diep, D.B.; Holo, H. Bacteriocin diversity in Streptococcus and Enterococcus. J. Bacteriol. 2007, 189, 1189-1198. [CrossRef] [PubMed]

53. Dahal, R.H.; Chaudhary, D.K.; Kim, D.-U.; Pandey, R.P.; Kim, J. Chryseobacterium antibioticum sp. nov. with antimicrobial activity against Gram-negative bacteria, isolated from Arctic soil. J. Antibiot. 2021, 74, 115-123. [CrossRef] [PubMed]

54. Hong, C.E.; Kim, J.U.; Lee, J.W.; Bang, K.H.; Jo, I.-H. Complete genome sequence of the Endophytic bacterium Chryseobacterium indologenes PgBE177, isolated from Panax quinquefolius. Microbiol. Resour. Announc. 2018, 7, e01234-18. [CrossRef]

55. Ugras, S.; Demirbag, Z. Screening antibacterial activity of entomopathogenic bacteria isolated from pests of hazelnut. Biologia 2013, 68, 592-598. [CrossRef] 
56. Enfedaque, J.; Ferrer, S.; Guasch, J.F.; Regué, M.; Tomás, J. Bacteriocin 28b from Serratia marcescens N28b: Identification of Escherichia coli surface components involved in bacteriocin binding and translocation. Can. J. Microbiol. 1996, 42, 19-26. [CrossRef]

57. Li, X.; Tan, X.; Zhang, J.; Zhang, J. Complete genome sequences of one prodigiosin-producing Serratia marcescens strain ZPG19. Front. Bioeng. Biotechnol. 2021, 9, 665077. [CrossRef]

58. Shanks, R.M.Q.; Dashiff, A.; Alster, J.S.; Kadouri, D.E. Isolation and identification of a bacteriocin with antibacterial and antibiofilm activity from Citrobacter freundii. Arch. Microbiol. 2012, 194, 575-587. [CrossRef]

59. Mandal, S.M.; Sharma, S.; Pinnaka, A.K.; Kumari, A.; Korpole, S. Isolation and characterization of diverse antimicrobial lipopeptides produced by Citrobacter and Enterobacter. BMC Microbiol. 2013, 13, 1-9. [CrossRef]

60. Yoon, S.-H.; Ha, S.-M.; Kwon, S.; Lim, J.; Kim, Y.; Seo, H.; Chun, J. Introducing EzBioCloud: A taxonomically united database of $16 \mathrm{~S}$ rRNA gene sequences and whole-genome assemblies. Int. J. Syst. Evol. Microbiol. 2017, 67, 1613-1617. [CrossRef]

61. Higgins, D.; Sharp, P. CLUSTAL: A package for performing multiple sequence alignment on a microcomputer. Gene 1988, 73, 237-244. [CrossRef]

62. Tamura, K.; Stecher, G.; Peterson, D.; Filipski, A.; Kumar, S. MEGA6: Molecular evolutionary genetics analysis version 6.0. Mol. Biol. Evol. 2013, 30, 2725-2729. [CrossRef]

63. Alzohairy, A. BioEdit: An important software for molecular biology. GERF Bull. Biosci. 2011, 2, 60-61.

64. Saitou, N.; Nei, M. The neighbor-joining method: A new method for reconstructing phylogenetic trees. Mol. Biol. Evol. 1987, 4, 406-425. [CrossRef] [PubMed]

65. Felsenstein, J. Confidence limits on phylogenies: An approach using the bootstrap. Evolution 1985, 39, 783-791. [CrossRef] [PubMed] 